\title{
Epidemiology and disease burden of tuberculosis in children: a global perspective
}

\author{
This article was published in the following Dove Press journal: \\ Infection and Drug Resistance \\ 18 June 2014 \\ Number of times this article has been viewed
}

\author{
James A Seddon' \\ Delane Shingadia ${ }^{2}$ \\ 'Department of Paediatric Infectious \\ Diseases, Imperial College London, \\ London, UK; ${ }^{2}$ Department of \\ Paediatric Infectious Diseases, Great \\ Ormond Street Hospital, London, UK
}

Correspondence: Delane Shingadia Department of Paediatric Infectious Diseases, Great Ormond Street Hospital, Great Ormond Street, London, UK Tel +442078138504

Fax +44 2078138552

Email delane.shingadia@gosh.nhs.uk

\begin{abstract}
Our understanding of the tuberculosis (TB) epidemic in children is incomplete due to challenges in diagnosis and reporting. Children have also been largely excluded from research and advocacy. However, the tide appears to be turning and interest in pediatric TB is increasing. In this article, we explore the epidemiology of childhood TB by first reviewing the natural history of TB in children and the factors that impact on each of the stages from exposure to disease. We then discuss how these factors affect what we see at a country and regional level. Finally, we assess the burden of childhood TB globally.
\end{abstract}

Keywords: tuberculosis, children, epidemiology, burden, global

\section{Introduction}

Children with tuberculosis (TB) have historically been neglected by clinicians, policy makers, academics, and advocates. In part, this has been due to the perception that children are rarely infectious, and consequently contribute little to the propagation of the epidemic; in part, because of the perception that they rarely develop severe disease; and in part, because in many countries, child health generally has not been important or prioritized. ${ }^{1}$ The World Health Organization (WHO) policy of targeting sputum smear-positive cases of TB for epidemic control, the directly observed treatment short-course (DOTS) strategy, largely ignores children, who rarely have sputum smear-positive TB. ${ }^{2}$

However, children with TB are important. Not only is there a clinical imperative to identify, diagnose, and treat children for a disease that is curable, but by ignoring childhood TB, efforts at epidemic TB control will ultimately fail. This is because children provide the reservoir out of which future cases will develop. Without the successful detection and treatment of TB infection and disease in children, elimination strategies will be ineffective.

Over the last few years, however, interest in childhood TB has increased dramatically. For the first time ever, in 2012, the WHO included an estimate for childhood TB in their annual report ${ }^{3}$ and in 2012, the focus of World TB Day was children. ${ }^{4}$ The TB Alliance, in 2013, was awarded up to $\$ 16.7$ million from UNITAID to develop child-friendly formulations for TB drugs for children ${ }^{5}$ and in 2013, the childhood TB roadmap was launched with a clear vision of what would be required to eliminate childhood TB. ${ }^{6}$

\section{Epidemiology}

When considering the epidemiology of childhood TB, it is important to consider which children develop TB, when they develop TB, where they develop TB, and why. 
Understanding the epidemiology helps clinicians make an assessment of the probability that the child in front of him/ her has TB. It also determines the pre-test probability of TB prior to investigation, thereby influencing the interpretation of these tests. On a programmatic level, it is important for policy makers and public health workers to design services and allocate resources. Finally, only by understanding the epidemiology and burden can we advocate appropriately for children with TB.

In considering the epidemiology of childhood TB, a number of stages will be discussed. First, we will discuss the natural history of TB in children and the factors that influence it. Second, we will explore how this translates into the varying epidemics that are seen in different countries. Finally, we will assess what this means in terms of the overall burden.

\section{Natural history}

For a child to develop TB, they must first be exposed to an infectious case of pulmonary TB, usually, but not always, from an adult. The Mycobacterium tuberculosis bacilli must reach the terminal alveoli and then overcome the innate immune system. Once the child is sensitized to the TB antigen and produces a positive test of infection (either a tuberculin skin test [TST] or an interferon-gamma release assay [IGRA]), they are said to have TB infection. At some point in the future, the bacilli will overcome the immune system and multiply in number. When the child develops the symptoms and signs of illness they are said to have TB disease. Certain risk factors determine the risk of exposure, and further factors then determine the risk of progression from exposure to infection and from infection to disease (Figure 1). These will be discussed in turn. The relationship between TB and poverty is compelling and confounds almost every other risk factor. ${ }^{7}$ Not only is poverty associated with increased risk of a child being exposed to TB, it also influences the risk of becoming infected and also of then developing disease.

\section{Exposure to tuberculosis}

Probably the greatest influence on the risk of TB exposure for a child is the background prevalence of TB in a community. The child has far higher risk of TB exposure in high TB prevalence regions. It is important to note, however, that TB prevalence is very heterogeneous in many countries, with different epidemics frequently existing alongside each other. ${ }^{8,9}$ This will be discussed later. Population density will also influence the risk of a child coming into contact with an infectious TB case, as more dense populations lead to more human encounters and encounters of more intense and prolonged physical proximity.

The age of the child will influence their risk of TB exposure, as older children interact with more adults in their day-to-day life. They can therefore be exposed to infectious cases of TB at home or in the community. Younger, especially pre-school, children interact with fewer adults, and generally come into contact with adults only in their family units. This will reduce their chances of being exposed to an adult with infectious TB. In addition to the age of the child, the household composition, the physical structure of the house, and the sleeping practices of the society will influence the risk of exposure. On an individual basis, the human density within a house will impact on the risk of exposure to a TB source case. Children living in houses with multiple adults are more likely to come into contact with an infectious case. In some societies, children sleep together in one room with adults in another, while in other communities, core family units sleep in the same room.

The weather in a community can influence exposure in a number of ways. Temperature and rainfall can influence how much time children spend outside in relative safety and how much time they spend indoors potentially exposed. Window opening will directly impact on ventilation ${ }^{10}$ and is in turn influenced by temperature. Wind speed can also impact on ventilation both outside and through windows. ${ }^{11}$ Sunlight will determine vitamin D levels among children, which will be discussed later when considering the risk of infection and disease progression. Seasonal peaks in childhood TB have been described in different communities and likely reflect a mixture of environment-related exposure factors combined with vitamin D levels. ${ }^{12-17}$

How a child lives will influence their risk of exposure to a TB source case. If children are taken on public transport systems, taken to sporting, family, or religious gatherings, or if children attend such activities on their own, they are likely to be at increased risk of exposure to TB. The cultural practices surrounding childcare and school within a community can also have a direct impact on TB exposure. ${ }^{18}$ Class size in school, ventilation, and mixed age classes can also affect the risk of exposure.

The issues of human immunodeficiency virus (HIV) and alcohol may impact on TB exposure, as both epidemics have an intimate and complex relationship with TB. HIV-infected adults are at significantly increased risk of TB disease. ${ }^{19,20}$ Children living with HIV-infected adults are likely to be at an increased risk of being HIV-infected themselves, and are therefore at an increased risk of being exposed to TB. 


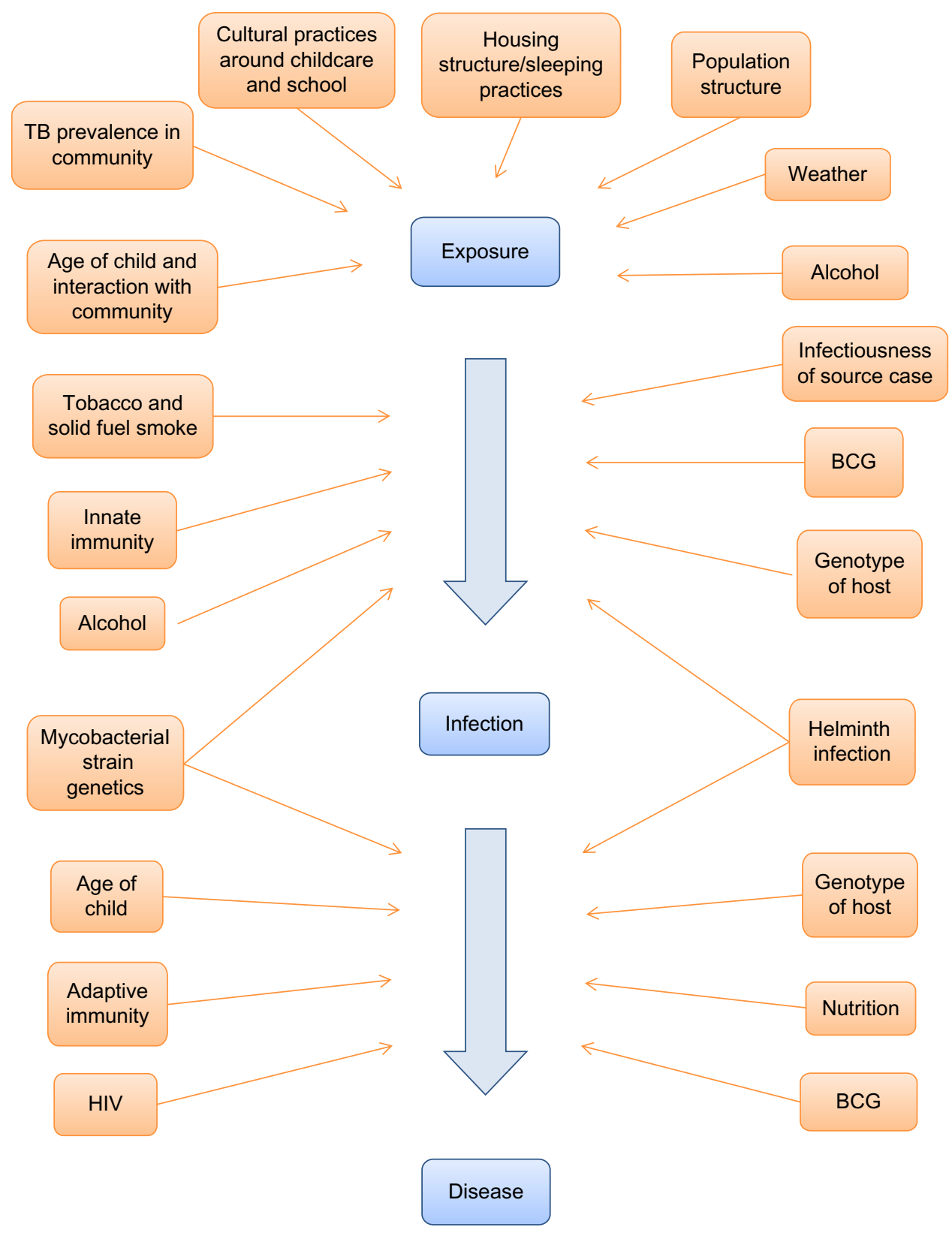

Figure I Risk factors for tuberculosis exposure, infection and disease in children.

Abbreviations: BCG, Bacillus Calmette-Guérin; HIV, human immunodeficiency virus; TB, tuberculosis.

Those who abuse alcohol are more likely to be exposed to TB due to behavioral practices and by attending places that are more likely to have other TB source cases. They are more likely to develop TB due to impaired immunity, are less likely to seek care, and also are less likely to have successful treatment. ${ }^{21}$ All of these factors lead to increased risk of TB exposure for children living in alcohol-affected households.

\section{M. tuberculosis infection}

Following exposure, the risk that a child will develop $M$. tuberculosis infection will be influenced by the infectiousness of the source case, the duration of the interaction, the intensity of the interaction, the infectiousness of the organism, and the immunology of the child. ${ }^{22,23}$

Source cases are more infectious if they are sputum smearpositive compared to sputum smear-negative, ${ }^{24,25}$ and although HIV-infected TB cases are considered poor producers of sputum, the evidence that they are less infectious is mixed. ${ }^{26-29}$ The bacterial load in the sputum influences infectivity. Sputum is graded using a logarithmic scale with one plus $(+)$ containing 1-99 bacilli per 100 fields, two pluses (++) 1-10 bacilli per field, and three pluses $(+++)>10$ bacilli per field. 
Higher bacterial loads are associated with increased risk of transmission..$^{24,30}$ In addition, more extensive pulmonary disease, defined as affecting multiple zones on a chest radiograph, is associated with increased risk of TST positivity in the contact, independent of mycobacterial load. ${ }^{24,31,32}$ The duration of cough has been shown to affect transmission, with children more likely to be infected if the source case has been coughing for a longer period of time. ${ }^{32,33}$

First-degree relatives are more likely to transmit mycobacteria that result in child contacts becoming infected than more distant relatives, and children sleeping in the same room as source cases are more likely to have a positive TST than those sleeping in different rooms. ${ }^{31,32,34-36}$ The physical proximity of how close a child sleeps to a source case influences transmission, ${ }^{22,31,32}$ but general markers of crowding are also associated with risk of childhood infection. ${ }^{22}$ The influence of solid fuel smoke and cigarette smoke is complex but children are more likely to become infected if someone in the house smokes cigarettes or if solid fuels are used to cook or for heating. ${ }^{22,25,37-39}$ This may be a result of impaired mucosal integrity, mucosal immunity, or inhibition of macrophage or $\mathrm{T}$ cell function..$^{40,41}$

The evidence around whether certain mycobacterial strains are more infectious is similarly confusing. There is some evidence to suggest that the Beijing strain is more likely to transmit and cause disease than other strains. ${ }^{42}$ However, other studies have failed to demonstrate this relationship. ${ }^{43,44}$ Some studies suggest that Bacillus Calmette-Guérin (BCG) vaccination provides less protection from Beijing as opposed to other strains, ${ }^{45}$ and there appears to be a strong relationship between Beijing and drug resistance. ${ }^{40,41}$ Whilst older studies in guinea pigs suggested that isoniazid-resistant strains were less infectious, ${ }^{46}$ more recent studies in human populations have not shown drug-resistant strains to be less infectious. $^{47-51}$

Most contact studies demonstrate that as children become older they are more likely to have a positive test of infection. ${ }^{32,52,53}$ As these tests reflect infection at any time in their life, these results are not surprising, as older children are more likely to have been exposed to infectious cases of TB in the community in addition to the identified source case. Whether uninfected older children are more likely than uninfected younger children to develop a positive infection test following known exposure is unclear. Outbreak investigations in low prevalence settings suggest that perhaps younger children are more vulnerable, but this may be explained by increased intensity of exposure. ${ }^{54}$ Although BCG has well-established efficacy against the progression from TB infection to severe forms of disease, there is emerging evidence that it may also protect against the establishment of infection. ${ }^{55-58}$ Many of these studies have employed IGRAs to detect TB infection following exposure, as it is not confounded by BCG and so this effect has only recently been possible to fully explore. Another issue that can impact on the risk of infection following exposure is parasitic infections. Studies have demonstrated that helminth infections can either increase ${ }^{59}$ or reduce $^{60}$ the risk of TST positivity following exposure to an infectious source case, and other studies tentatively suggest that protozoa infections may protect against TB infection..$^{59,61}$ Finally, our understanding of genetic susceptibility to TB has improved dramatically since the development of genomewide association studies. These suggest that certain genes may play an important role in determining susceptibility, ${ }^{62,63}$ particularly vitamin D receptor polymorphisms. ${ }^{64}$

\section{Tuberculosis disease}

From studies that examined the natural history of TB, conducted prior to the chemotherapy era, we know that following infection, age plays one of the most significant roles in determining which children will progress to disease. Infected infants (those less than 12 months of age) have a $50 \%$ risk of progression to disease. Children from 1-2 years have a $20 \%-30 \%$ risk, those from $3-5$ years a risk of $5 \%$, those 5-10 years old only a $2 \%$ risk and older children an adult-like risk (5\%). ${ }^{65-67}$ Young children are also more likely to develop the most severe forms of TB, such as TB meningitis or military TB. HIV also plays a significant role. In the absence of anti-retroviral therapy, adults with HIV and TB infection have a 7\%-10\% risk of developing TB each year. ${ }^{19,20}$ Infants (children $<12$ months) with HIV are twenty times as likely to develop TB as children without HIV. ${ }^{68}$ Children who are malnourished or who have other forms of immune deficiency have been shown to be more vulnerable as well. ${ }^{69}$ Another significant factor in determining the likelihood of progression is how recently a child was infected. If a child is going to develop disease, the majority will progress within 12 months of infection..$^{50,70}$ Therefore, children infected more than 1 year ago are less likely to progress than children recently infected.

BCG has been shown in many studies to protect children from the development of TB disease, with the effect most marked for young children and against the most severe, extrapulmonary forms of TB. ${ }^{71-73}$ However, the protective effect of BCG seems to vary depending on the location that it is used; it has been suggested that its efficacy wanes towards the equator. This may be due to either masking or interaction 
with non-tuberculous mycobacteria, which are more common in tropical locations. ${ }^{74}$ Both mycobacterial and host genotypes also seem to influence the risk of progression. Beijing strain has been shown in some studies to be associated with disseminated disease in adults. ${ }^{42,75,76}$ However, this pattern has not been demonstrated in children. ${ }^{77}$ Certain host genes are more common in people who develop TB disease than those who do not, as described above. ${ }^{62,63}$

\section{Regional epidemiology of pediatric tuberculosis}

Donald has suggested that one of the main factors contributing to the importance of childhood TB in developing communities is the shape of the population pyramid; in many developing countries, between $40 \%$ and $50 \%$ of the population are under the age of 15 years. ${ }^{8,9}$ Figure 2 shows the age- and gender-related incidence in a hypothetical highincidence community and contrasts this with a low-incidence community. In low-incidence communities, TB becomes confined to the older generations with fewer children and less frequent exposure to adults with pulmonary disease. In highincidence communities, in addition to more children, there is also increased exposure to adults with pulmonary disease due to sociodemographic factors such as overcrowding, etc. The split between high- and low-incidence communities may therefore be artificial and sometimes overlapping populations may coexist within the same geographical regions. This is frequently seen in Western European cities, where TB prevalence in some administrative regions can be greater than ten times that of the region next to them. ${ }^{78}$

Another consequence of varying population structures, again described by Donald, ${ }^{79}$ is that in high prevalence regions, not only are more children exposed (due to the higher force of infection and a larger proportion of children in the community), but children are also exposed at a younger age and consequently are more likely to progress to disease. He suggested that a relationship exists between the prevalence of TB in a community and the proportion of TB that is found in children. With incidence rates of $10 / 100,000$, the proportion of cases found in children is less than $10 \%$, but this increases to $40 \%$ where the incidence is $1,000 / 100,000$.

\section{European region}

TB case notifications in Europe make up less than $10 \%$ of worldwide notifications to the WHO. ${ }^{3}$ Case notifications reveal disparities between countries in the European Union (EU) and the non-EU countries, particularly those in Eastern Europe, comprising mostly states of the former Soviet Union. Table 1 shows the TB cases in children and adults in the European Region in 2011, broken down by EU and non-EU countries (adapted from the European Centre for Disease Prevention and Control/WHO Regional Office for Europe; Tuberculosis surveillance and monitoring in Europe). ${ }^{80}$

In EU Member States, pediatric case notifications ranged from $0.3 / 100,000$ to $29.6 / 100,000$ in 2009. Overall, notification rates have dropped from 5.5/100,000 in 2000 to $4.2 / 100,000$ in $2009 .{ }^{81}$ Of all pediatric cases reported from 2000 to 2009 , only $16.9 \%$ were culture-confirmed. Further breakdown of TB cases in children by age group and origin in some EU Member States show interesting variations (Table 2). Romania and Spain account for the largest numbers on children notified from any of the EU Member States, with most children being native-born and only a minority being foreign-born. However, a three-decade review of TB in

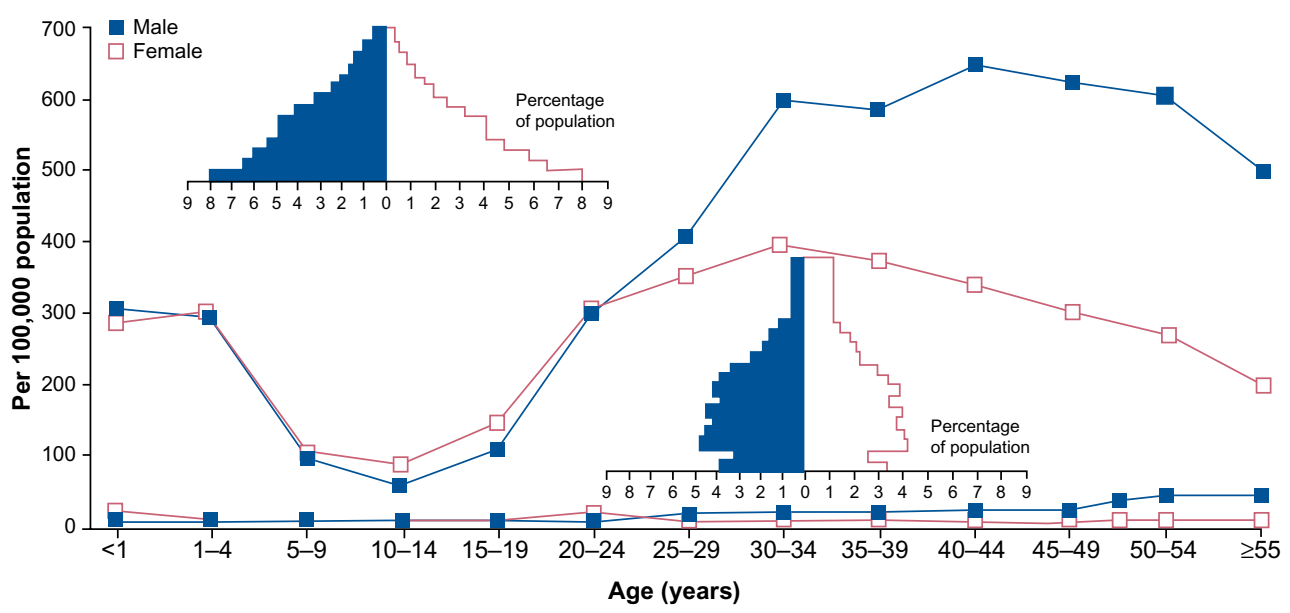

Figure 2 Age- and gender-related differences of tuberculosis incidence in hypothetical high and low tuberculosis incidence populations.

Notes: Reproduced with permission of the International Union Against Tuberculosis and Lung Disease. Copyright () The Union. Donald PR. Childhood tuberculosis: the hidden epidemic. Int J Tuberc Lung Dis. 2004;8(5):627-629. ${ }^{8}$ 
Table I Tuberculosis cases in adults and children within the European region in 201 I

\begin{tabular}{|c|c|c|c|c|c|c|}
\hline \multirow[t]{2}{*}{ Area } & \multicolumn{3}{|c|}{ Age $\leq 15$ years } & \multicolumn{3}{|c|}{ Age $>15$ years } \\
\hline & $\begin{array}{l}\text { Number of } \\
\text { cases }\end{array}$ & $\begin{array}{l}\text { Percentage of } \\
\text { total burden* }\end{array}$ & $\begin{array}{l}\text { Incidence (number of } \\
\text { cases/ I 00,000 per year) }\end{array}$ & $\begin{array}{l}\text { Number of } \\
\text { cases }\end{array}$ & $\begin{array}{l}\text { Percentage of } \\
\text { total burden* }\end{array}$ & $\begin{array}{l}\text { Incidence (number of } \\
\text { cases/100,000 per year) }\end{array}$ \\
\hline EU & 3,190 & 4.4 & 4.0 & 69,084 & 95.5 & 16.1 \\
\hline Non-EU & 8,762 & 2.9 & 11.2 & 210,206 & 69.1 & 66.6 \\
\hline Total ER & 11,952 & 3.2 & 7.6 & 279,290 & 75.2 & 37.6 \\
\hline
\end{tabular}

Note: *Percentages calculation based on all cases with age notified.

Abbreviations: EU, European Union; ER, European region.

Spanish children has suggested that the proportion of cases diagnosed in immigrant children has risen from $2 \%$ to $46 \% .{ }^{82}$ In France and the UK, larger numbers of foreign-born children are being seen, particularly in the 5-14 year age groups. This reflects the overall changes in TB epidemiology in those countries, with overall increases in foreign-born individuals. ${ }^{78}$ Figure 3 demonstrates this relationship in the UK.

These data also suggest two concurrent epidemiological patterns as described by Donald above, a low-incidence picture of mainly UK-born individuals skewed towards older age groups, presumably infected in childhood, and a high-incidence picture of non-UK-born young adults and their children, presumably infected in their countries of origin. Of interest are younger children in the $<5$ year age group who are predominantly all UK-born and probably reflecting transmission from their non-UK-born parents. Epidemiological studies in children with TB in the UK would suggest higher rates in different ethnic groups, with rates in the black African ethnic group of 88/100,000 compared with $1.1 / 100,000$ in the white ethnic group. ${ }^{83}$ This trend is particularly pronounced in urban centers in the UK such as London, ${ }^{84}$ Birmingham, ${ }^{85}$ and Leeds. ${ }^{86}$ Similar patterns have occurred in other low-prevalence countries in Europe such as Sweden, ${ }^{87}$ Norway ${ }^{88}$ and Denmark. ${ }^{89}$

Pediatric data from non-EU Member States from the European Region are more limited. In the ECDC 2013 report, the seven countries with the highest reported rates of pediatric TB in 2011 were: Kyrgyzstan 31.1/100,000, Georgia 28.8/100,000, Tajikistan 22.3/100,000, Uzbekistan
21.8/100,000, Russia 16.2/100,000, Armenia 8.2/100,000, and Ukraine 8.0/100,000.$^{80}$ In contrast to EU Member States, TB in these countries occurs predominantly in country-born children rather than foreign-born children. The emergence of drug-resistant TB has been an important issue in this region, although pediatric data are limited in national surveillance studies. Although it is believed that drug resistance in children is both underestimated and underreported, the studies that do exist suggest that within countries, the proportion of pediatric cases with drug resistance is similar to the proportion in adults..$^{90}$

\section{African region}

After the Southeast Asian region, the African region has the largest numbers of children being reported, particularly from Sub-Saharan African countries, which make up a large proportion of high-burden countries listed by the WHO. ${ }^{3}$ Many of the countries in this region are resource-poor, making reliable estimates of TB incidence difficult, especially in children. Lack of resources makes accurate diagnosis of TB cases more difficult, and in many countries, TB control programs rely almost exclusively on sputum microscopy for the diagnosis of TB, as part of WHO TB control strategies. This means that TB in children is both undiagnosed and underreported. Inadequate health information and surveillance systems in many countries may also contribute to inaccuracies in the available data. One study in the Western Cape of South Africa showed that of 689 cases of TB meningitis in children aged $<14$ years, only $55 \%$ had been notified. ${ }^{91}$

Table 2 Tuberculosis cases in children ( $\leq 15$ years old), by age group and origin in the EU in $201 \mathrm{I}$

\begin{tabular}{|c|c|c|c|c|c|c|c|c|c|c|c|c|c|c|c|c|}
\hline \multirow[t]{3}{*}{ Country } & \multicolumn{4}{|c|}{ Native } & \multicolumn{4}{|c|}{ Foreign origin } & \multicolumn{4}{|c|}{ Unknown } & \multicolumn{4}{|l|}{ Total } \\
\hline & \multicolumn{2}{|c|}{$<5$ years } & \multicolumn{2}{|c|}{ 5- 15 years } & \multicolumn{2}{|c|}{$<5$ years } & \multicolumn{2}{|c|}{ 5- 15 years } & \multicolumn{2}{|c|}{$<5$ years } & \multicolumn{2}{|c|}{ 5-1 5 years } & \multicolumn{2}{|c|}{$<\mathbf{5}$ years } & \multicolumn{2}{|c|}{$5-15$ years } \\
\hline & $\mathbf{N}$ & $\%$ & $\mathbf{N}$ & $\%$ & $\mathbf{N}$ & $\%$ & $\mathbf{N}$ & $\%$ & $\mathbf{N}$ & $\%$ & $\mathbf{N}$ & $\%$ & $\mathbf{N}$ & $\%$ & $\mathbf{N}$ & $\%$ \\
\hline France & 101 & 63.5 & 58 & 36.5 & 20 & 23 & 67 & 77 & 4 & 44.4 & 5 & 55.6 & 125 & 49 & 130 & 51 \\
\hline Romania & 299 & 38 & 472 & 61.2 & 4 & 80 & I & 20 & 0 & 0 & 0 & 0 & 303 & 39 & 473 & 61 \\
\hline Spain & 267 & 63 & 157 & 37 & 31 & 28.4 & 78 & 71.6 & 3 & 37.5 & 5 & 62.5 & 301 & 55.6 & 240 & 44.4 \\
\hline UK & 116 & 44.6 & 144 & 55.4 & 18 & 12.9 & 121 & 87.1 & 6 & 42.9 & 8 & 57.1 & 140 & 33.9 & 273 & 66.1 \\
\hline Total EU & $\mathrm{I}, \mathrm{I} 74$ & 46.6 & I,334 & 53.4 & 159 & 25.6 & 462 & 74.4 & 20 & 39.2 & 31 & 60.8 & I,353 & 42.4 & I,837 & 57.6 \\
\hline
\end{tabular}

Abbreviation: EU, European Union. 


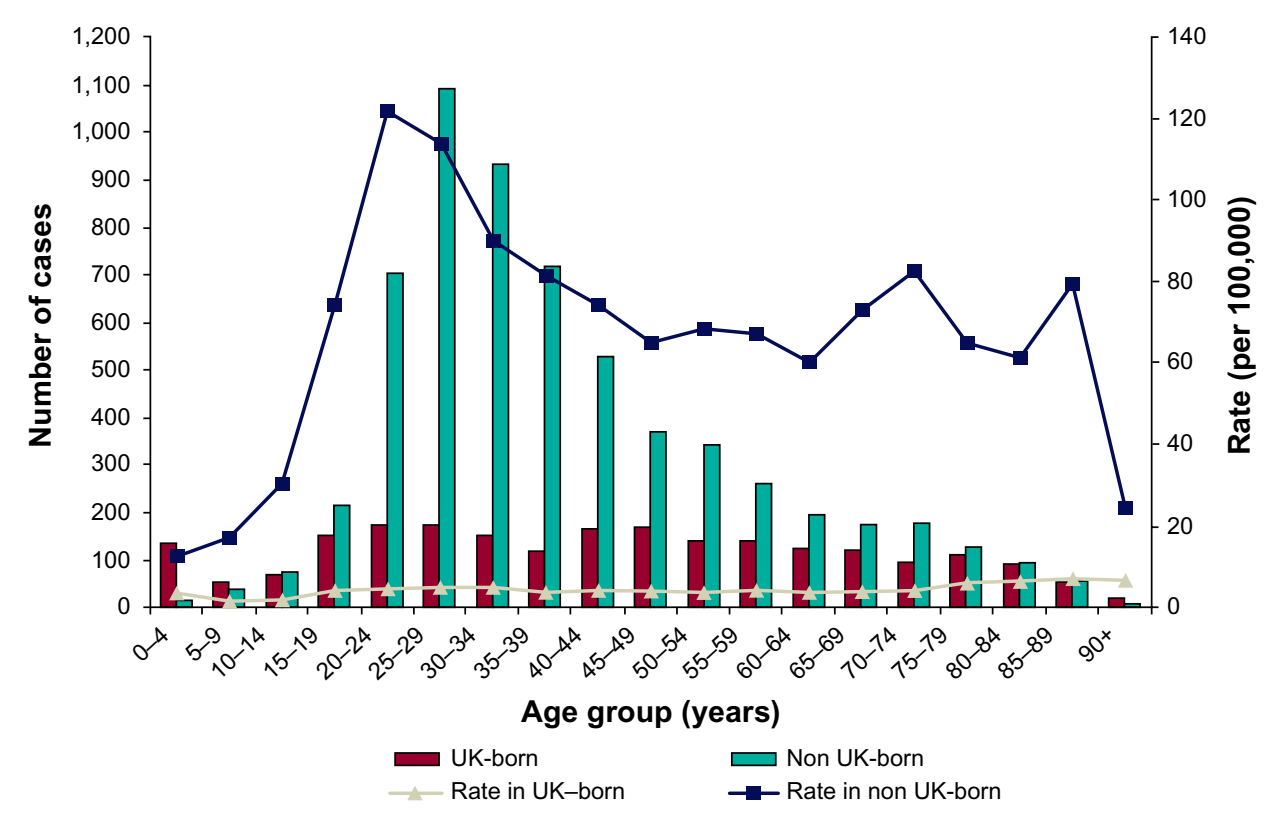

Figure 3 Tuberculosis case reports and rates by age group and place of birth, UK, 2012.

Notes: Reproduced from Public Health England. Tuberculosis in the UK 2013 Report. Public Health England: London, UK; 20I3. Available from: http://www.hpa.org.uk/webc/ HPAwebFile/HPAweb_C/I3I7I39689583. ${ }^{78}$ @ Crown copyright 2013.

It is clear is that in Sub-Saharan Africa, pediatric cases make up a substantially higher proportion of overall TB cases than in other countries. Estimates based on TB prevalence suggest proportions in excess of $20 \% .^{79}$ Although these estimates are open to dispute, several studies in resource-poor countries would agree with this figure. ${ }^{92,93}$ A study in an urban community in the Western Cape Province of South Africa (overall TB incidence estimated $1,149 / 100,000$ ) found that $39 \%$ of the caseload was due to children younger than 14 years of age..$^{94}$ Furthermore, the greatest burden of TB in children appears to be between $12-23$ months of age (1.2/100 person years) with the highest disease severity in this age group..$^{95}$ While some countries have reported declines in TB incidence in children, others have reported dramatic increases, particularly with HIV coinfection, which has been estimated to occur in $8 \%-55 \%$ of newly diagnosed children with TB. ${ }^{95,96}$

A retrospective review of TB notifications in the Kilimanjaro region of Kenya showed that children constituted $13 \%$ of all TB burden with average case detection rates of 147/100,000 for urban and 41.8/100,000 for rural populations..$^{97}$ Of the minority of children who were tested for HIV infection, $82 \%$ tested positive. Of children diagnosed with TB, only $24.9 \%$ had samples tested for acid fast bacilli using Ziehl-Neelsen staining with no other microbiological testing such as culture or drug susceptibility testing. Recently, increasing drug resistance, particularly multi-drug-resistant (MDR; M. tuberculosis resistant to at least rifampicin and isoniazid) TB, has been reported in children in Cape Town, South Africa but this is likely to be underreported in other parts of Africa without access to culture or drug resistance testing. ${ }^{98}$

\section{Southeast Asian region}

The Southeast Asia region has the largest number of people with TB in the world, with almost ten times as many case notifications in children as Europe in 2012. Although three countries from this region (India, Indonesia, and Bangladesh) are in the top four high-burden countries listed by the $\mathrm{WHO},{ }^{3}$ there is little information on the rates of pediatric TB. Chakraborty estimated that approximately 10 million children in India each year are at risk of being infected because of contact with a smearpositive adult. ${ }^{99}$ Given that $5 \%$ could be expected to develop TB in the first 2 years following infection and another $2 \%-3 \%$ over the next 2 years, he estimated that $700,000-800,000$ children would develop TB over the subsequent 5 years. If this was the case, over 80,000 children could be expected to die or suffer serious disability over the same 5-year period.

In Thailand, a surveillance study of four provinces and one national hospital for 1 year showed that only $279(2 \%)$ of 14,487 total cases occurred in children, with $27 \%$ having HIV coinfection and only one case of MDR-TB. The investigators propose that the infrequent diagnosis of TB in children may either reflect an absence of disease or underreporting due to difficulties in diagnosing TB in children. ${ }^{100}$ 


\section{Western Pacific region}

TB case notification figures for the Western Pacific region from the WHO are dominated by the People's Republic of China, which has the second largest number of new TB cases in the world. ${ }^{3}$ This is mostly due to its vast population. Apart from the People's Republic of China, the Western Pacific region is mostly made up of small nations, generally with estimated TB rates of less than 50/100,000. While the rates of TB have increased in the last 5 years in some countries, only Vietnam shows increases in rates similar to those in highburden Sub-Saharan African countries. In Taiwan, nationwide data from the National TB Registry show that the incidence of TB in persons $<20$ years of age was $9.61 / 100,000$ person-years. However, the overall childhood TB incidence in Aboriginal children was 81.5/100,000 person-years which was almost ten times higher than for non-Aboriginal children. The higher rates in Aboriginal children were attributed to lower socioeconomic status and inherited susceptibility, in addition to increased risk of exposure. ${ }^{101}$

An Australian study also demonstrated clearly how immigration from high-prevalence countries can contribute significantly to the disease pattern within a low-prevalence population. Heath et al studied TB surveillance data for New South Wales between 1975 and $1995 .{ }^{102}$ During this period, the overall TB notification rates for the Australian-born population fell exponentially to around $2 / 100,000$, while the percentage of notifications in those born overseas rose from $30 \%$ to $79 \%$. In children $<15$ years of age over this time period, rates initially fell, but rose again from 1992 to 1995 . Notification rates were highest in children born overseas, while $51 \%$ of Australianborn children with TB were from non-English speaking households. Similarly, a retrospective review of pediatric TB in New Zealand showed a resurgence of TB, predominantly involving non-European and immigrant groups. ${ }^{103}$

\section{Eastern Mediterranean region}

In general, TB notifications to the WHO in this region have remained unchanged, or have fallen since the later part of the last decade. This region does not contribute substantially to the worldwide burden of TB, and has the lowest rates of disease in all the WHO regions. The country with the largest population in the region, Pakistan, had a significant reduction in TB notifications between 1980 and 2001. However, case detection rates in Pakistan are very low, with the WHO estimating that only $10 \%$ of sputum smear-positive cases are being detected. ${ }^{3}$ A small study from Iran carried out between 1999 and 2004 demonstrated low levels of drug resistance among M. tuberculosis isolates from children. ${ }^{104}$

\section{American region}

The total number of TB case notifications for this region has remained remarkably constant since 1980 . This is despite the two countries with the greatest number of TB cases, Brazil and US, having both had steady decreases in case notifications since 1998. Overall, TB cases in the US peaked in 1992, and have been steadily falling since that time. In 2012, the Centers for Disease Control and Prevention (CDC) reported an estimated overall TB rate of 3.2/100,000 with a $62 \%$ reduction in the number of $\mathrm{TB}$ cases reported annually since the peak in $1992 .{ }^{105,106}$

In the US, national rates in children $<18$ years of age have followed a similar pattern to that seen in adult TB, falling from 2.1/100,000 in 1994 to $1.1 / 100,000$ in $2007 .{ }^{107} \mathrm{~TB}$ rates among foreign-born children and adolescents also declined from 20.3/100,000 to $11.4 / 100,000$ but remained higher than US-born children. Among foreign-born children with known month of US entry, more than $20 \%$ were diagnosed with TB within 3 months of entry. In a subsequent surveillance study, over three-quarters of pediatric patients with TB in the US had potential TB exposures through foreign-born parents or residence outside the US. ${ }^{108}$ In Canada, a school-based TB-screening program for recently immigrated children demonstrated that $21 \%$ were TST positive. ${ }^{109}$

Although there are few epidemiological studies on pediatric TB in South America and patchy national reporting, a number of hospital-based studies have documented the presentation and management of children with TB. In Brazil, from 1999-2008, 473 children were treated at one teaching hospital, two-thirds with a known TB contact, the majority of those in the household. ${ }^{110}$ Seventeen percent were HIVpositive and a confirmed diagnosis was made in $31 \%$ of cases. In Peru, 2,392 children were described as having TB over a 25 -year period. ${ }^{111}$ Only $0.1 \%$ was found to be HIV-positive and the median age was 9 years. Mortality in this cohort was $11 \%$, which was associated with young age and lack of response to tuberculin skin testing.

\section{Global burden}

There are a number of challenges to estimating the burden of TB in children. Most estimates use the number of reported pediatric cases as the starting point to estimate the burden. In many countries, not all children started on treatment are reported to the National TB Program. ${ }^{12}$ Some children are simply missed, and in other countries, only confirmed cases are reported. Further, pediatric TB can be difficult to diagnose and many children with TB are never started on appropriate treatment. This is due to three factors. First, a confirmed diagnosis 
Table 3 New tuberculosis case notifications in 2012, by case type and age disaggregation

\begin{tabular}{|c|c|c|c|}
\hline & $\begin{array}{l}\text { Smear- } \\
\text { positive }\end{array}$ & $\begin{array}{l}\text { Smear- } \\
\text { negative* }\end{array}$ & $\begin{array}{l}\text { Extra- } \\
\text { pulmonary }\end{array}$ \\
\hline Total notifications & $2,568,789$ & $1,935,971$ & 817,462 \\
\hline Countries disaggregating by age & $2,551,136$ & $\mathrm{I}, 597,530$ & 678,953 \\
\hline $\begin{array}{l}\text { Countries not disaggregating } \\
\text { by age (percentage of total } \\
\text { notifications disaggregated) }\end{array}$ & $\begin{array}{l}17,653 \\
(99 \%)\end{array}$ & $\begin{array}{l}338,44 \mathrm{I} \\
(83 \%)\end{array}$ & $\begin{array}{l}138,509 \\
(83 \%)\end{array}$ \\
\hline $\begin{array}{l}\text { Number of countries that } \\
\text { reported notifications } \\
\text { disaggregated by age (number } \\
\text { of high-burden countries)** }\end{array}$ & $204(22)$ & $184(14)$ & $184(14)$ \\
\hline $\begin{array}{l}\text { Total childhood notifications } \\
\text { from countries disaggregating } \\
\text { by age }\end{array}$ & 46,488 & 163,477 & 91,308 \\
\hline $\begin{array}{l}\text { Total estimated childhood } \\
\text { notification among all countries }\end{array}$ & 349,000 & & \\
\hline
\end{tabular}

Notes: *This includes reported cases for whom smear results were unknown or not done; **an additional nine countries reported zero tuberculosis cases for 2012 and three countries had not reported data to the World Health Organization by July 2013.

can be challenging due to difficulties in the collection of clinical samples, as well as low rates of culture-confirmation in those for whom samples are collected. ${ }^{113}$ Second, a clinical diagnosis can also be challenging, as unlike adults where the signs and symptoms of TB are relatively sensitive and specific, TB in children can be non-specific, ${ }^{114}$ and in many parts of the world where TB prevalence is high, other diseases exist with overlapping features. Finally, in remote and rural areas of the world, it is likely that many children are never brought to the attention of medical services once symptomatic.

The WHO estimated that there were $530,000 \mathrm{~TB}$ cases in children in 2012 and 74,000 deaths among children who were HIV-negative. ${ }^{115}$ The global number of TB case notifications among children (aged $<15$ years) was estimated at 349,000 in 2012 (Table 3). This includes cases reported from children and an estimate of the number of cases among children in countries that did not report notifications disaggregated by age. To estimate TB incidence among children, it was assumed that the case detection rate for all ages at the global level in 2012 (best estimate 66\%, range 64\%-69\%) was the same for adults and children (Figure 4). On this basis, TB incidence among children was estimated to be 530,000 (range $510,000-550,000)$ in 2012 , equivalent to about $6 \%$ of the total number of 8.6 million incident cases. Limitations of this methods include: 1) the assumption that the case detection rate is the same for adults and children, in the absence of any data on levels of underreporting of the diagnosed cases for children and adults separately; 2) the assumption that reported cases were true cases of TB; and 3) the proportion of cases among children may be different in countries for which disaggregated data were not available. The regional breakdown of new TB case notifications in 2012, by age, sex, and WHO region is shown in Table 4 (adapted from the Global Tuberculosis Report 2013). ${ }^{3}$

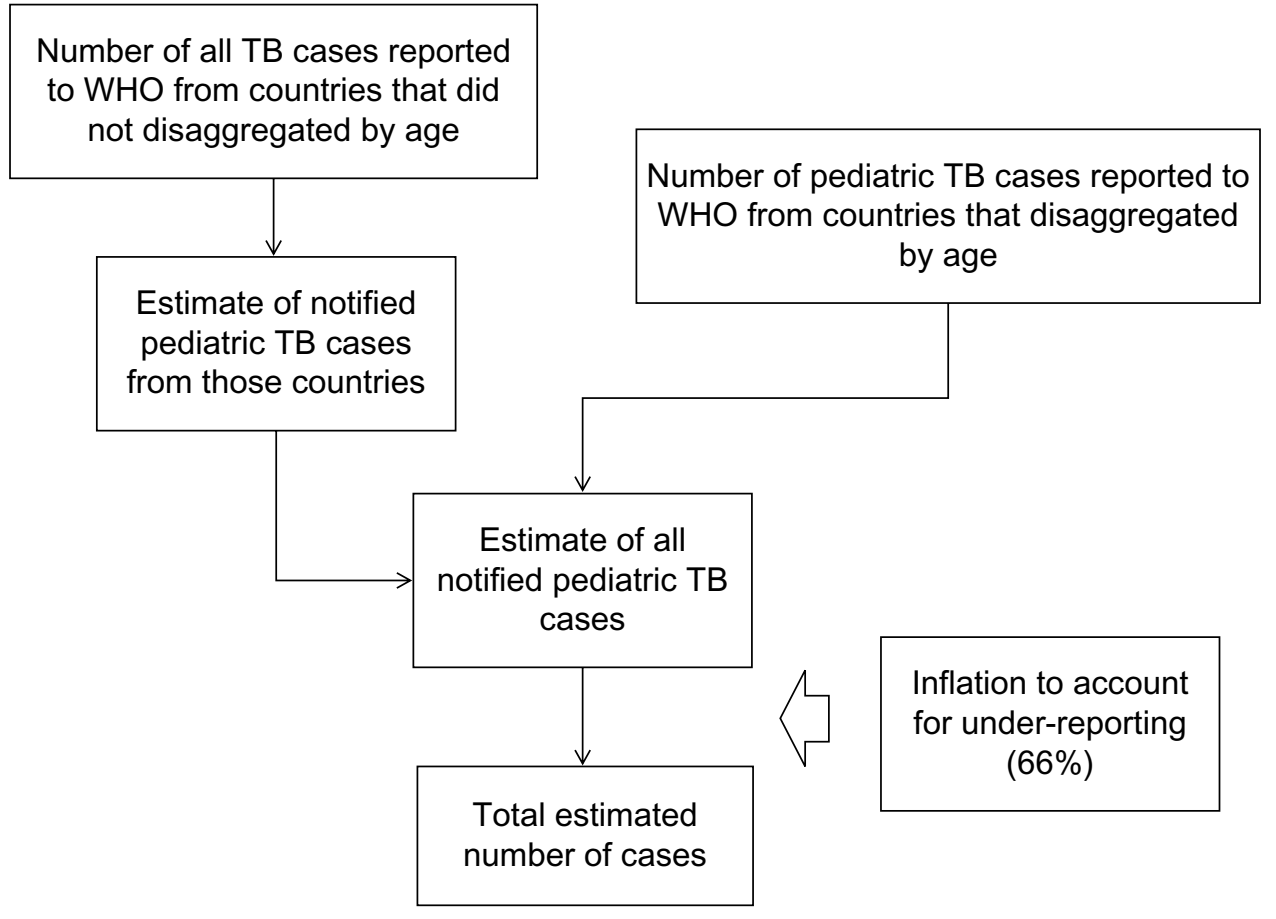

Figure 4 The strategy employed by the World Health Organization to arrive at the estimate of childhood tuberculosis cases. Abbreviations: TB, tuberculosis; WHO, World Health Organization. 
Table 4 The regional breakdown of new tuberculosis case notifications in 20II, by age and World Health Organization region

\begin{tabular}{|c|c|c|c|c|c|c|}
\hline & $0-14$ years & I 5-44 years & $45-64$ years & $\geq 65$ years & $\%$ Aged $<\mathbf{I 5}$ years & $\begin{array}{l}\text { Male/female } \\
\text { ratio }\end{array}$ \\
\hline Afghanistan & 669 & 8,574 & 3,319 & 1,227 & 5 & 0.51 \\
\hline Bangladesh & 932 & 53,585 & 30,877 & 13,554 & $<1$ & 1.9 \\
\hline Brazil & 692 & 25,270 & $\mathrm{II}, 080$ & 3,211 & 2 & 2.2 \\
\hline Cambodia & 73 & 6,810 & 6,412 & $2,58 I$ & $<1$ & 1.2 \\
\hline People's Republic of China & I,378 & 173,523 & 128,585 & 73,519 & $<1$ & 2.6 \\
\hline DR Congo & 3,379 & 47,529 & 17,207 & 3,206 & 5 & 1.2 \\
\hline Ethiopia & 3,830 & 38,518 & 6,272 & $\mathrm{I}, 074$ & 8 & 1.2 \\
\hline India & 12,985 & 388,447 & 187,705 & 53,174 & 2 & 2.2 \\
\hline Indonesia & I,7|4 & || $5,63 \mid$ & 67,378 & 13,074 & $<1$ & 1.5 \\
\hline Kenya & 985 & 29,884 & 5,207 & 1,009 & 3 & 1.6 \\
\hline Mozambique & & & & & - & - \\
\hline Myanmar & 307 & 23,902 & 14,198 & 3,907 & $<1$ & 1.9 \\
\hline Nigeria & $\mathrm{I}, 107$ & 34,559 & 9,604 & 2,167 & 2 & 1.6 \\
\hline Pakistan & 3,895 & 64,309 & 27,495 & 10,034 & 4 & I.I \\
\hline Philippines & 953 & 51,919 & 31,069 & 6,935 & 1 & 2.4 \\
\hline Russian Federation & 51 & 18,066 & 9,477 & I,597 & $<1$ & 2.7 \\
\hline South Africa & 3,404 & 94,427 & 27,552 & 4,387 & 3 & 1.2 \\
\hline Thailand & 114 & 14,980 & 11,862 & 6,213 & $<1$ & 2.4 \\
\hline Uganda & 695 & 18,486 & 4,842 & 917 & 3 & 1.8 \\
\hline UR Tanzania & 411 & 17,149 & 5,047 & $\mathrm{I}, 508$ & 2 & 1.8 \\
\hline Vietnam & 95 & 23,404 & $|8,27|$ & 8,949 & $<1$ & 3.0 \\
\hline Zimbabwe & 326 & 9,953 & I,879 & 438 & 3 & 1.2 \\
\hline High-burden countries & 37,995 & $1,258,925$ & 625,338 & $2|2,68|$ & 2 & 1.9 \\
\hline Africa & 19,183 & 427,731 & $1 \mid 4,303$ & 23,574 & 3 & 1.4 \\
\hline America & 2,337 & 62,127 & 27,495 & ||$, 3||$ & 2 & 1.8 \\
\hline Eastern Mediterranean & 5,763 & 105,833 & 42,736 & 16,303 & 3 & 1.2 \\
\hline Europe & 391 & 46,807 & 24,197 & 6,962 & $<1$ & 2.3 \\
\hline Southeast Asia & 17,144 & 626,659 & 329,687 & 93,857 & 2 & 2.0 \\
\hline Western Pacific & 2,880 & 272,434 & 196,490 & 104,444 & $<1$ & 2.4 \\
\hline Global & 47,698 & $I, 54 I, 59 \mid$ & 734,908 & 256,45 I & 2 & 1.9 \\
\hline
\end{tabular}

Notes: Reproduced with permission from the World Health Organization. Global Tuberculosis Report. Geneva: World Health Organization; 20I2: WHO/HTM/TB/20I2.6. Available from: http://apps.who.int/iris/bitstream//0665/75938/I/978924I564502_eng.pdf. ${ }^{3}$ Copyright @ 2012, World Health Organization.

Almost all (96\%) of the notifications of new smearpositive cases were disaggregated by age, of which $2 \%$ or 42,127 cases were in children aged $<15$ years. Reporting of cases disaggregated by age and sex was much less complete for smear-negative pulmonary and extrapulmonary cases. When the available data for all new cases were combined, $6 \%$ or 292,295 cases were among children $<15$ years. The Southeast Asian region accounted for the largest number of new cases, with a total of 119,186 cases, followed by the African region with 97,629 cases.

An alternative attempt to estimate the burden of childhood TB was carried out using 2000 data. ${ }^{116,117}$ It used, as a starting point, estimates of smear-positive TB for different age groups, in each of the 22 high-burden countries. These were then combined with estimates of the proportion of cases expected to be smear-positive for each age group to calculate the total number of cases in each age group. This technique produced an estimate for the 22 high-burden countries of 659,397 pediatric $(<15$ years) cases or $9.6 \%$ of the burden in those countries. When extrapolated to all countries, the approach yielded an estimate of 884,019 pediatric cases globally.

\section{Conclusion}

It is important to understand both the natural history and epidemiology of childhood TB in order to assess which children are the most vulnerable and also to begin to understand the burden on a regional, national, or global level. It is also important as it allows appropriate targeting of health resources and for purposes of advocacy. Currently, estimates of burden are somewhat incomplete due to imperfect diagnosis, recording, and reporting, as well as by limitations to the methodology used to make 
estimates from the number of cases reported. However, the tide appears to be turning and it is hoped that the TB epidemic in children will be more completely understood in the coming years.

\section{Disclosure}

The authors report no conflicts of interest in this work.

\section{References}

1. Marais BJ, Gie RP, Schaaf HS, Beyers N, Donald PR, Starke JR. Childhood pulmonary tuberculosis: old wisdom and new challenges. Am J Respir Crit Care Med. 2006;173(10):1078-1090.

2. World Health Organization. Tuberculosis Programme: framework for effective tuberculosis control. Geneva, Switzerland: World Health Organization; 1994: (WHO/TB/94.179).

3. World Health Organization. Global Tuberculosis Report. Geneva: World Health Organization; 2012: WHO/HTM/TB/2012.6. Available from: http://apps.who.int/iris/bitstream/10665/75938/1/9789241564502_eng. pdf. Accessed August 1, 2013.

4. Stop TB Partnership [webpage on the Internet]. World TB Day message from Dr Lucica Ditiu, Executive Secretary of the Stop TB Partnership [March 24, 2013]. Available at: http://www.stoptb.org/news/ stories/2012/ns12_027.asp. Accessed October 1, 2013.

5. TB Alliance. TB Alliance Receives Grant from UNITAID to Develop Pediatric TB Drugs [December 20, 2012]. Available at: http://www. tballiance.org/newscenter/view-brief.php?id=1058\#sthash.xLlC3Bn0. dpufhttp://www.tballiance.org/newscenter/view-brief.php?id=1058. Accessed October 1, 2013.

6. World Health Organization. Roadmap for Childhood Tuberculosis. Geneva, World Health Organization; 2013. Available from: http:/ apps.who.int/iris/bitstream/10665/89506/1/9789241506137_eng.pdf. Accessed October 1, 2013.

7. Janssens JP, Rieder HL. An ecological analysis of incidence of tuberculosis and per capita gross domestic product. Eur Respir J. 2008;32(5):1415-1416.

8. Donald PR. Childhood tuberculosis: the hidden epidemic. Int J Tuberc Lung Dis. 2004;8(5):627-629.

9. Donald PR, Marais BJ, Barry CE 3rd. Age and the epidemiology and pathogenesis of tuberculosis. Lancet. 2010;375(9729):1852-1854.

10. Lygizos M, Shenoi SV, Brooks RP, et al. Natural ventilation reduces high TB transmission risk in traditional homes in rural KwaZulu-Natal, South Africa. BMC Infect Dis. 2013;13:300.

11. Escombe AR, Oeser CC, Gilman RH, et al. Natural ventilation for the prevention of airborne contagion. PLoS Med. 2007;4(2):e68.

12. Schaaf HS, Nel ED, Beyers N, Gie RP, Scott F, Donald PR. A decade of experience with Mycobacterium tuberculosis culture from children: a seasonal influence on incidence of childhood tuberculosis. Tuber Lung Dis. 1996;77(1):43-46.

13. Koh GC, Hawthorne G, Turner AM, Kunst H, Dedicoat M. Tuberculosis incidence correlates with sunshine: an ecological 28-year time series study. PLoS One. 2013;8(3):e57752.

14. Parrinello CM, Crossa A, Harris TG. Seasonality of tuberculosis in New York City, 1990-2007. Int J Tuberc Lung Dis. 2012;16(1):32-37.

15. Korthals Altes H, Kremer K, Erkens C, van Soolingen D, Wallinga J. Tuberculosis seasonality in the Netherlands differs between natives and non-natives: a role for vitamin D deficiency? Int J Tuberc Lung Dis. 2012;16(5):639-644.

16. Willis MD, Winston CA, Heilig CM, Cain KP, Walter ND, Mac Kenzie WR. Seasonality of tuberculosis in the United States, 1993-2008. Clin Infect Dis. 2012;54(11):1553-1560.

17. Maclachlan JH, Lavender CJ, Cowie BC. Effect of latitude on seasonality of tuberculosis, Australia, 2002-2011. Emerg Infect Dis. 2012;18(11):1879-1881.
18. Wood R, Racow K, Bekker LG, et al. Indoor social networks in a South African township: potential contribution of location to tuberculosis transmission. PLoS One. 2012;7(6):e39246.

19. Guelar A, Gatell JM, Verdejo J, et al. A prospective study of the risk of tuberculosis among HIV-infected patients. AIDS. 1993;7(10): 1345-1349.

20. Selwyn PA, Hartel D, Lewis VA, et al. A prospective study of the risk of tuberculosis among intravenous drug users with human immunodeficiency virus infection. $N$ Engl J Med. 1989;320(9):545-550.

21. Lonnroth K, Williams BG, Stadlin S, Jaramillo E, Dye C. Alcohol use as a risk factor for tuberculosis - a systematic review. BMC Public Health. 2008;8:289.

22. Tipayamongkholgul M, Podhipak A, Chearskul S, Sunakorn P. Factors associated with the development of tuberculosis in BCG immunized children. Southeast Asian J Trop Med Public Health. 2005;36(1): $145-150$.

23. Lienhardt C. From exposure to disease: the role of environmental factors in susceptibility to and development of tuberculosis. Epidemiol Rev. 2001;23(2):288-301.

24. Gessner BD, Weiss NS, Nolan CM. Risk factors for pediatric tuberculosis infection and disease after household exposure to adult index cases in Alaska. J Pediatr. 1998;132(3 Pt 1):509-513.

25. Singh M, Mynak ML, Kumar L, Mathew JL, Jindal SK. Prevalence and risk factors for transmission of infection among children in household contact with adults having pulmonary tuberculosis. Arch Dis Child. 2005;90(6):624-628.

26. Cruciani M, Malena M, Bosco O, Gatti G, Serpelloni G. The impact of human immunodeficiency virus type 1 on infectiousness of tuberculosis: a meta-analysis. Clin Infect Dis. 2001;33(11):1922-1930.

27. Escombe AR, Moore DA, Gilman RH, et al. The infectiousness of tuberculosis patients coinfected with HIV. PLoS Med. 2008;5(9):e188.

28. Carvalho AC, DeRiemer K, Nunes ZB, et al. Transmission of Mycobacterium tuberculosis to contacts of HIV-infected tuberculosis patients. Am J Respir Crit Care Med. 2001;164(12):2166-2171.

29. Huang CC, Tchetgen ET, Becerra M, et al. The effect of HIV-related immunosuppression on the risk of tuberculosis transmission to household contacts. Clin Infect Dis. 2014;58(6):765-774.

30. Shaw JB, Wynn-Williams N. Infectivity of pulmonary tuberculosis in relation to sputum status. Am Rev Tuberc. 1954;69(5):724-732.

31. Lienhardt C, Fielding K, Sillah J, et al. Risk factors for tuberculosis infection in sub-Saharan Africa: a contact study in The Gambia. Am J Respir Crit Care Med. 2003;168(4):448-455.

32. Lienhardt C, Sillah J, Fielding K, et al. Risk factors for tuberculosis infection in children in contact with infectious tuberculosis cases in the Gambia, West Africa. Pediatrics. 2003;111(5 Pt 1):e608-e614.

33. Loudon RG, Spohn SK. Cough frequency and infectivity in patients with pulmonary tuberculosis. Am Rev Respir Dis. 1969;99(1):109-111.

34. Rouillon A, Perdrizet S, Parrot R. Transmission of tubercle bacilli: the effects of chemotherapy. Tubercle. 1976;57(4):275-299.

35. Andersen S, Geser A. The distribution of tuberculous infection among households in African communities. Bull World Health Organ. 1960;22:39-60.

36. Narain R, Nair SS, Rao GR, Chandrasekhar P. Distribution of tuberculous infection and disease among households in a rural community. Bull World Health Organ. 1966;34(4):639-654.

37. den Boon S, Verver S, Marais BJ, et al. Association between passive smoking and infection with Mycobacterium tuberculosis in children. Pediatrics. 2007;119(4):734-739.

38. Lienhardt C, Fielding K, Sillah JS, et al. Investigation of the risk factors for tuberculosis: a case-control study in three countries in West Africa. Int J Epidemiol. 2005;34(4):914-923.

39. Lin HH, Ezzati M, Murray M. Tobacco smoke, indoor air pollution and tuberculosis: a systematic review and meta-analysis. PLoS Med. 2007;4(1):e20.

40. Feng Y, Kong Y, Barnes PF, et al. Exposure to cigarette smoke inhibits the pulmonary T-cell response to influenza virus and Mycobacterium tuberculosis. Infect Immun. 2011;79(1):229-237. 
41. van Zyl-Smit RN, Binder A, Meldau R, et al. Cigarette smoke impairs cytokine responses and BCG containment in alveolar macrophages. Thorax. 2014;69(4):363-370.

42. Hanekom M, van der Spuy GD, Streicher E, et al. A recently evolved sublineage of the Mycobacterium tuberculosis Beijing strain family is associated with an increased ability to spread and cause disease. J Clin Microbiol. 2007;45(5):1483-1490.

43. Marais BJ, Hesseling AC, Schaaf HS, Gie RP, van Helden PD, Warren RM. Mycobacterium tuberculosis transmission is not related to household genotype in a setting of high endemicity. J Clin Microbiol. 2009;47(5):1338-1343.

44. Langlois-Klassen D, Senthilselvan A, Chui L, et al. Transmission of Mycobacterium tuberculosis Beijing Strains, Alberta, Canada, 1991-2007. Emerg Infect Dis. 2013;19(5):701-711.

45. Lopez B, Aguilar D, Orozco H, et al. A marked difference in pathogenesis and immune response induced by different Mycobacterium tuberculosis genotypes. Clin Exp Immunol. 2003;133(1): 30-37.

46. Middlebrook G, Cohn ML. Some observations on the pathogenicity of isoniazid-resistant variants of tubercle bacilli. Science. 1953;118(3063): 297-299.

47. Barroso E, Mota R, Pinheiro V, Campelo C, Rodrigues J. Occurence of active tuberculosis in households inhabited by patients with susceptible and multidrug-resistant tuberculosis. Jornal Brasileiro de Pneumologia. 2004;30(4):401-408.

48. Snider DE Jr, Kelly GD, Cauthen GM, Thompson NJ, Kilburn JO. Infection and disease among contacts of tuberculosis cases with drugresistant and drug-susceptible bacilli. Am Rev Respir Dis. 1985;132(1): $125-132$.

49. Teixeira L, Perkins MD, Johnson JL, et al. Infection and disease among household contacts of patients with multidrug-resistant tuberculosis. Int J Tuberc Lung Dis. 2001;5(4):321-328.

50. Schaaf HS, Gie RP, Kennedy M, Beyers N, Hesseling PB, Donald PR. Evaluation of young children in contact with adult multidrug-resistant pulmonary tuberculosis: a 30-month follow-up. Pediatrics. 2002; 109(5):765-771.

51. Davies AP, Billington OJ, Bannister BA, Weir WR, McHugh TD, Gillespie SH. Comparison of fitness of two isolates of Mycobacterium tuberculosis, one of which had developed multi-drug resistance during the course of treatment. J Infect. 2000;41(2):184-187.

52. Rutherford ME, Hill PC, Maharani W, et al. Risk factors for Mycobacterium tuberculosis infection in Indonesian children living with a sputum smear-positive case. Int J Tuberc Lung Dis. 2012;16(12): 1594-1599.

53. Seddon JA, Hesseling AC, Godfrey-Faussett P, Fielding K, Schaaf HS. Risk factors for infection and disease in child contacts of multidrugresistant tuberculosis: a cross-sectional study. BMC Infect Dis. 2013; 13(1):392.

54. Gillman A, Berggren I, Bergstrom SE, Wahlgren H, Bennet R. Primary tuberculosis infection in 35 children at a Swedish day care center. Pediatr Infect Dis J. 2008;27(12):1078-1082.

55. Soysal A, Millington KA, Bakir M, et al. Effect of BCG vaccination on risk of Mycobacterium tuberculosis infection in children with household tuberculosis contact: a prospective community-based study. Lancet. 2005;366(9495):1443-1451.

56. Basu Roy R, Sotgiu G, Altet-Gomez N, et al. Identifying predictors of interferon-gamma release assay results in pediatric latent tuberculosis: a protective role of bacillus Calmette-Guerin?: a pTB-NET collaborative study. Am J Respir Crit Care Med. 2012;186(4):378-384.

57. Eriksen J, Chow JY, Mellis V, et al. Protective effect of BCG vaccination in a nursery outbreak in 2009: time to reconsider the vaccination threshold? Thorax. 2010;65(12):1067-1071.

58. Eisenhut M, Paranjothy S, Abubakar I, et al. BCG vaccination reduces risk of infection with Mycobacterium tuberculosis as detected by gamma interferon release assay. Vaccine. 2009;27(44):6116-6120.

59. Verhagen LM, Hermans PW, Warris A, et al. Helminths and skewed cytokine profiles increase tuberculin skin test positivity in Warao Amerindians. Tuberculosis (Edinb). 2012;92(6):505-512.
60. van Soelen N, Mandalakas AM, Kirchner HL, et al. Effect of Ascaris Lumbricoides specific IgE on tuberculin skin test responses in children in a high-burden setting: a cross-sectional community-based study. BMC Infect Dis. 2012;12:211.

61. Franke MF, Del Castillo H, Pereda Y, et al. Modifiable factors associated with tuberculosis disease in children: a case-control study. Pediatr Infect Dis J. 2014;33(1):109-111.

62. Qu HQ, Fisher-Hoch SP, McCormick JB. Knowledge gaining by human genetic studies on tuberculosis susceptibility. J Hum Genet. 2011;56(3):177-182.

63. Moller M, de Wit E, Hoal EG. Past, present and future directions in human genetic susceptibility to tuberculosis. FEMS Immunol Med Microbiol. 2010;58(1):3-26.

64. Gao L, Tao Y, Zhang L, Jin Q. Vitamin D receptor genetic polymorphisms and tuberculosis: updated systematic review and meta-analysis. Int J Tuberc Lung Dis. 2010;14(1):15-23.

65. Marais BJ, Gie RP, Schaaf HS, et al. The clinical epidemiology of childhood pulmonary tuberculosis: a critical review of literature from the pre-chemotherapy era. Int J Tuberc Lung Dis. 2004;8(3):278-285.

66. Marais BJ, Gie RP, Schaaf HS, et al. The natural history of childhood intra-thoracic tuberculosis: a critical review of literature from the prechemotherapy era. Int J Tuberc Lung Dis. 2004;8(4):392-402.

67. Comstock GW, Livesay VT, Woolpert SF. The prognosis of a positive tuberculin reaction in childhood and adolescence. Am J Epidemiol. 1974;99(2):131-138.

68. Hesseling AC, Cotton MF, Jennings T, et al. High incidence of tuberculosis among HIV-infected infants: evidence from a South African population-based study highlights the need for improved tuberculosis control strategies. Clin Infect Dis. 2009;48(1):108-114.

69. Jaganath D, Mupere E. Childhood tuberculosis and malnutrition. $J$ Infect Dis. 2012;206(12):1809-1815.

70. Ferebee SH. Controlled chemoprophylaxis trials in tuberculosis. A general review. Bibl Tuberc. 1970;26:28-106.

71. Trunz BB, Fine P, Dye C. Effect of BCG vaccination on childhood tuberculous meningitis and miliary tuberculosis worldwide: a metaanalysis and assessment of cost-effectiveness. Lancet. 2006;367(9517): 1173-1180.

72. Rodrigues LC, Diwan VK, Wheeler JG. Protective effect of BCG against tuberculous meningitis and miliary tuberculosis: a meta-analysis. Int $J$ Epidemiol. 1993;22(6):1154-1158.

73. Colditz GA, Berkey CS, Mosteller F, et al. The efficacy of bacillus Calmette-Guerin vaccination of newborns and infants in the prevention of tuberculosis: meta-analyses of the published literature. Pediatrics. 1995;96(1 Pt 1):29-35.

74. Fine PE. Variation in protection by BCG: implications of and for heterologous immunity. Lancet. 1995;346(8986):1339-1345.

75. Thwaites G, Caws M, ChauTT, et al. Relationship between Mycobacterium tuberculosis genotype and the clinical phenotype of pulmonary and meningeal tuberculosis. J Clin Microbiol. 2008;46(4):1363-1368.

76. Caws M, Thwaites G, Dunstan S, et al. The influence of host and bacterial genotype on the development of disseminated disease with Mycobacterium tuberculosis. PLoS Pathog. 2008;4(3):e1000034.

77. Maree F, Hesseling AC, Schaaf HS, et al. Absence of an association between Mycobacterium tuberculosis genotype and clinical features in children with tuberculous meningitis. Pediatr Infect Dis J. 2007;26(1): 13-18.

78. Public Health England. Tuberculosis in the UK 2013 Report. Public Health England: London, UK; 2013. Available from: http://www. hpa.org.uk/webc/HPAwebFile/HPAweb_C/1317139689583. Accessed November 1, 2013.

79. Donald PR. Childhood tuberculosis: out of control? Curr Opin Pulm Med. 2002;8(3):178-182.

80. European Centre for Disease Prevention and Control/WHO Regional Office for Europe. Tuberculosis Surveillance and Monitoring in Europe. European Centre for Disease Prevention and Control/WHO Regional Office for Europe: København, Denmark; 2013. Available from: http://www.ecdc.europa.eu/en/publications/Publications/ Tuberculosis-surveillance-monitoring-2013.pdf. Accessed December $18,2013$. 
81. Sandgren A, Hollo V, Quinten C, Manissero D. Childhood tuberculosis in the European Union/European Economic Area, 2000 to 2009. Euro Surveill. 2011;16(12). pii:19825.

82. del Rosal T, Baquero-Artigao F, Garcia-Miguel MJ, et al. Impact of immigration on pulmonary tuberculosis in Spanish children: a threedecade review. Pediatr Infect Dis J. 2010;29(7):648-651.

83. Abubakar I, Laundy MT, French CE, Shingadia D. Epidemiology and treatment outcome of childhood tuberculosis in England and Wales: 1999-2006. Arch Dis Child. 2008;93(12):1017-1021.

84. Ruwende JE, Sanchez-Padilla E, Maguire H, Carless J, Mandal S, Shingadia D. Recent trends in tuberculosis in children in London. J Public Health (Oxf). 2011;33(2):175-181.

85. Bakhshi SS, Hawker J, Ali S. The epidemiology of tuberculosis by ethnic group in Birmingham and its implications for future Trends in tuberculosis in the UK. Ethn Health. 1997;2(3):147-153.

86. Parslow R, El-Shimy NA, Cundall DB, McKinney PA. Tuberculosis, deprivation, and ethnicity in Leeds, UK, 1982-1997. Arch Dis Child. 2001;84(2):109-113.

87. Nejat S, Buxbaum C, Eriksson M, Pergert M, Bennet R. Pediatric tuberculosis in Stockholm: a mirror to the world. Pediatr Infect Dis J. 2012;31(3):224-227.

88. Krogh K, Suren P, Mengshoel AT, Brandtzaeg P. Tuberculosis among children in Oslo, Norway, from 1998 to 2009. Scand J Infect Dis. 2010;42(11-12):866-872.

89. Hatleberg C, Prahl JB, Rasmussen JN, et al. A review of paediatric tuberculosis in Denmark: ten year trend, 2000-2009. Eur Respir J. 2014;43(3):863-871

90. Zignol M, Sismanidis C, Falzon D, Glaziou P, Dara M, Floyd K. Multidrug-resistant tuberculosis in children: evidence from global surveillance. Eur Respir J. 2013;42(3):701-707.

91. Berman S, Kibel MA, Fourie PB, Strebel PM. Childhood tuberculosis and tuberculous meningitis: high incidence rates in the Western Cape of South Africa. Tuber Lung Dis. 1992;73(6):349-355.

92. Murray CJ, Styblo K, Rouillon A. Tuberculosis in developing countries: burden, intervention and cost. Bull Int Union Tuberc Lung Dis. 1990;65(1):6-24.

93. Harries AD, Parry C, Nyongonya Mbewe L, et al. The pattern of tuberculosis in Queen Elizabeth Central Hospital, Blantyre, Malawi: 1986-1995. Int J Tuberc Lung Dis. 1997;1(4):346-351.

94. van Rie A, Beyers N, Gie RP, Kunneke M, Zietsman L, Donald PR Childhood tuberculosis in an urban population in South Africa: burden and risk factor. Arch Dis Child. 1999;80(5):433-437.

95. Moyo S, Verver S, Mahomed H, et al. Age-related tuberculosis incidence and severity in children under 5 years of age in Cape Town, South Africa. Int J Tuberc Lung Dis. 2010;14(2):149-154.

96. Cavanaugh J, Genga K, Marigu I, Laserson K, Ackers M, Cain K. Tuberculosis among children in Kenya: epidemiology and impact of HIV in two provinces. J Trop Pediatr. 2012;58(4):292-296.

97. Mtabho CM, Irongo CF, Boeree MJ, Aarnoutse RE, Kibiki GS Childhood tuberculosis in the Kilimanjaro region: lessons from and for the TB programme. Trop Med Int Health. 2010;15(5):496-501.

98. Seddon JA, Hesseling AC, Marais BJ, Jordaan A, Victor T, Schaaf HS. The evolving epidemic of drug-resistant tuberculosis among children in Cape Town, South Africa. Int J Tuberc Lung Dis. 2012;16(7): 928-933.

99. Chakraborty A. Problem of tuberculosis among children in the community: situation analysis in the perspective of tuberculosis in India. Ind J Tuberc. 1999;46:91-103.

Infection and Drug Resistance

\section{Publish your work in this journal}

Infection and Drug Resistance is an international, peer-reviewed openaccess journal that focuses on the optimal treatment of infection (bacterial, fungal and viral) and the development and institution of preventive strategies to minimize the development and spread of resistance. The journal is specifically concerned with the epidemiology of antibiotic
100. Lolekha R, Anuwatnonthakate A, Nateniyom S, et al. Childhood TB epidemiology and treatment outcomes in Thailand: a TB active surveillance network, 2004 to 2006. BMC Infect Dis. 2008;8:94.

101. Chan PC, Huang LM, Wu YC, et al. Tuberculosis in children and adolescents, Taiwan, 1996-2003. Emerg Infect Dis. 2007;13(9):1361-1363.

102. Heath TC, Roberts C, Winks M, Capon AG. The epidemiology of tuberculosis in New South Wales 1975-1995: the effects of immigration in a low prevalence population. Int J Tuberc Lung Dis. 1998;2(8):647-654.

103. Howie S, Voss L, Baker M, Calder L, Grimwood K, Byrnes C. Tuberculosis in New Zealand, 1992-2001: a resurgence. Arch Dis Child. 2005;90(11):1157-1161.

104. Khalilzadeh S, Boloorsaz MR, Safavi A, Farnia P, Velayati AA. Primary and acquired drug resistance in childhood tuberculosis. East Mediterr Health J. 2006;12(6):909-914.

105. CDC. Reported Tuberculosis in the United States, 2012. Atlanta, GA: US Department of Health and Human Services, CDC; Oct 2013.

106. World Health Organization. Tuberculosis in the Americas: Regional Report 2012. Epidemiology, Control and Financing. Washington: Pan American Health Organization; 2012. Available from: http:// www.paho.org/hq/index.php?option=com_docman\&task=doc_ view\&gid=22953\&Itemid=. Accessed April 24, 2014.

107. Menzies HJ, Winston CA, Holtz TH, Cain KP, Mac Kenzie WR. Epidemiology of tuberculosis among US- and foreign-born children and adolescents in the United States, 1994-2007. Am J Public Health. 2010;100(9):1724-1729.

108. Winston CA, Menzies HJ. Pediatric and adolescent tuberculosis in the United States, 2008-2010. Pediatrics. 2012;130(6):e1425-e1432.

109. Brassard P, Steensma C, Cadieux L, Lands LC. Evaluation of a school-based tuberculosis-screening program and associate investigation targeting recently immigrated children in a low-burden country. Pediatrics. 2006;117(2):e148-e156.

110. Matos TP, Kritski AL, Ruffino Netto A. Epidemiological aspects of tuberculosis in children and adolescents in Rio de Janeiro. J Pediatr (Rio J). 2012;88(4):335-340.

111. Drobac PC, Shin SS, Huamani P, et al. Risk factors for in-hospital mortality among children with tuberculosis: the 25-year experience in Peru. Pediatrics. 2012;130(2):e373-e379.

112. Du Preez K, Schaaf HS, Dunbar R, et al. Incomplete registration and reporting of culture-confirmed childhood tuberculosis diagnosed in hospital. Public Health Action. 2011;1(1):19-24.

113. Zar HJ, Hanslo D, Apolles P, Swingler G, Hussey G. Induced sputum versus gastric lavage for microbiological confirmation of pulmonary tuberculosis in infants and young children: a prospective study. Lancet. 2005;365(9454):130-134.

114. Hesseling AC, Schaaf HS, Gie RP, Starke JR, Beyers N. A critical review of diagnostic approaches used in the diagnosis of childhood tuberculosis. Int J Tuberc Lung Dis. 2002;6(12):1038-1045.

115. World Health Organization. Global Tuberculosis Report. Geneva: World Health Organization; 2013. Available at: http:/www.who.int/tb/publications/global_report/en/index.html. Accessed December 18, 2013.

116. Corbett EL, Watt CJ, Walker N, et al. The growing burden of tuberculosis: global trends and interactions with the HIV epidemic. Arch Intern Med. 2003;163(9):1009-1021.

117. Nelson LJ, Wells CD. Global epidemiology of childhood tuberculosis. Int J Tuberc Lung Dis. 2004;8(5):636-647.

\section{Dovepress}

resistance and the mechanisms of resistance development and diffusion in both hospitals and the community. The manuscript management system is completely online and includes a very quick and fair peerreview system, which is all easy to use. Visit http://www.dovepress.com/ testimonials.php to read real quotes from published authors. 